\title{
Nonalcoholic steatohepatitis in nondiabetic obese patients
}

\author{
Idilio Zamin Jr MD, Angelo Alves de Mattos MD PhD, \\ Cláudio Galeano Zettler MD PhD
}

\begin{abstract}
I Zamin Jr, A Alves de Mattos, CG Zettler. Nonalcoholic steatohepatitis in nondiabetic obese patients. Can J Gastroenterol 2002;16(5):303-307.
\end{abstract}

BACKGROUND: Nonalcoholic steatohepatitis (NASH) is a major disorder in patients with persistent changes in aminotransferase activity who test negative for viral markers and autoantibodies. Although NASH has been correlated with obesity, no study has been carried out exclusively with nondiabetic obese patients.

OBJECTIVES: To evaluate the occurrence of NASH in obese patients without diabetes mellitus and to assess the severity of histological involvement of the liver.

PATIENTS AND METHODS: Serum aminotransferase levels were evaluated in 912 obese patients seen at an outpatient clinic in Porto Alegre, Brazil, from 1997 to 1999. Sixty-eight patients were found to have altered aminotransferase levels in more than one test. Thirty-five patients were excluded due to the presence of diabetes mellitus $(n=12)$, the presence of viral markers $(n=11)$, alcohol consumption $(n=8)$ and the use of hepatotoxic drugs $(n=4)$. NASH was diagnosed when histological findings revealed macrovesicular steatosis associated with lobular inflammatory infiltrate and hepatocellular injury.

RESULTS: Of the 912 obese patients studied, 33 patients with altered aminotransferase levels underwent liver biopsy. Four patients were excluded because they had steatosis only; the remaining 29 patients $(3.18 \%)$ fulfilled the diagnostic criteria established for NASH. The mean age of the 29 patients was $42.2 \pm 11.9$ years; $65.52 \%$ of the patients were women. Grading of histological findings revealed mild disease in $58.6 \%$ of cases; important proliferation of fibrous tissue was absent in most cases. CONCLUSIONS: NASH is a common disease among nondiabetic obese patients with altered aminotransferase levels, and it usually manifests as a mild clinical condition, although more severe lesions may be observed.

Key Words: Chronic hepatitis; Nonalcoholic steatohepatitis; Obesity

\section{La stéatohépatite non alcoolique chez les patients obèses non diabétiques}

HISTORIQUE : La stéatohépatite non alcoolique (SHNA) est un trouble important chez les patients présentant des modifications persistantes de l'activité de l'aminotransférase et dont les examens des marqueurs viraux et des auto-anticorps sont négatifs. Bien que la SHNA soit corrélée avec l'obésité, aucune étude n'a été effectuée exclusivement avec des non-diabétiques.

OBJECTIFS : Évaluer l'occurrence de SHNA chez les patients obèses non atteints de diabète sucré et la gravité de l'atteinte histologique du foie.

suite à la page suivante

Department of Gastroenterology, Santa Casa University Hospital, Fundação Faculdade Federal de Ciências Médicas de Porto Alegre (FFFCMPA), Brazil

Correspondence: Dr Idilio Zamin Júnior, Rua Carvalho Monteiro, 75/202 90470-100 Porto Alegre, RS, Brazil.

Telephone/fax +55-51-3395-4244, e-mail izamin@terra.com.br

Received for publication November 6, 2001. Accepted February 13, 2002 
PATIENTS ET MÉTHODOLOGIE : Les taux d'aminotransférase sérique ont été évalués chez 912 patients obèses vus en clinique externe à Porto Alegre, au Brésil, entre 1997 et 1999. Soixante-huit patients ont présenté une perturbation du taux d'aminostransférase à plus d'un examen. Trente-cinq ont été exclus en raison de la présence de diabète sucré ( $\mathrm{n}=12$ ) ou de marqueurs viraux ( $\mathrm{n}=11)$, de consommation d'alcool ( $\mathrm{n}$ $=8$ ) et de l'utilisation de drogues hépatotoxiques $(n=4)$. La SHNA a été diagnostiquée lorsque les observations histologiques ont révélé une stéatose macrovésiculaire associée à un infiltrat inflammatoire lobulaire et à une lésion hépatocellulaire.

RÉSULTATS : Sur les 912 patients étudiés, 33 présentant une perturba- tion du taux d'aminotransférase ont subi une biopsie hépatique. Quatre patients ont été exclus parce qu'ils souffraient d'une simple stéatose. Les 29 autres patients respectaient les critères diagnostiques établis pour la SHNA (31,8 \%). Ils avaient un âge moyen de 42,2 $\pm 11,9$ ans, et $65,52 \%$ d'entre eux étaient des femmes. Le classement des observations histologiques a révélé une maladie bénigne chez 58,6\% des sujets. Dans la plupart des cas, on remarquait l'absence d'une importante prolifération de tissu fibreux. CONCLUSIONS : La SHNA est une maladie courante chez les sujets obèses non diabétiques présentant une perturbation du taux d'aminotransférase, et cette maladie se manifeste généralement par un trouble clinique bénin. Des lésions plus graves peuvent cependant s'observer.
$I^{n}$ $\mathrm{n}$ the late 1970s, Schaffner and Adler (1) studied obese people with no history of excessive alcohol consumption and observed histological findings in the liver similar to those found in alcoholic patients. The term 'nonalcoholic steatohepatitis' (NASH) was first used in 1980 by Ludwig et al (2), who observed that NASH was associated with obesity and diabetes mellitus, and that it was more prevalent in women. Other investigators (3) showed that NASH can also occur in nonobese people and in men.

Subsequent studies (4-13) confirmed the report by Ludwig et al (2). Currently, NASH is considered to be a major disorder in nonalcoholic patients who present with persistent changes in aminotransferase activity and who test negative for viral markers and for autoantibodies (14). Another feature of NASH is its potential to progress to cirrhosis (2-8,10-13).

Although NASH has been correlated with obesity in several investigations (2,4-13), no study has been carried out exclusively with nondiabetic obese patients. Therefore, the objective of the present study was to assess the occurrence of NASH in nondiabetic obese patients and to evaluate the activity and the histological staging of the disease through liver biopsies.

\section{PATIENTS AND METHODS}

A prospective study was conducted in 912 consecutive obese patients seen at the Nutrition and Gastroenterology Outpatient Clinic at Irmandade Santa Casa de Misericórdia, Porto Alegre, Brazil, during a period of three years (1997 to 1999). Patients sought the clinic with the aim of losing weight. Obesity was defined as body mass index (BMI) higher than $30 \mathrm{~kg} / \mathrm{m}^{2}$ (15).

After the first visit and the clinical evaluation of nutritional status, all 912 patients underwent the following tests: fasting glycemia, cholesterol, triglycerides, alanine aminotransferase (ALT) and aspartate aminotransferase (AST). Sixty-eight patients had altered aminotransferase levels, but 12 were excluded because they had diabetes mellitus. Diabetes mellitus was diagnosed according to the recommendations of the American Diabetes Association (16). On the first return visit, 56 patients were informed about the test results and their possible implications, and then invited to participate in the study.
The 56 patients were investigated for possible risk factors for hepatic disease, with emphasis on alcohol consumption, use of potentially hepatotoxic drugs and occupational exposure to agents likely to cause liver damage. Patients presenting with any of these factors were excluded from the study. Excessive alcohol consumption was defined as the weekly ingestion of more than $40 \mathrm{~g}$ of ethanol, according to Powell et al (7). Other exclusion criteria were age below 18 years or over 65 years, and pregnancy. In this phase, 12 patients were excluded: eight were alcohol abusers, and four were taking hepatotoxic drugs (verapamil, captopril, enalapril).

The remaining 44 patients underwent the following laboratory tests: blood count, platelet count, bilirubin level, ALT level, AST level, alkaline phosphatase level, gammaglutamyl transpeptidase level, prothrombin time, serum protein electrophoresis, serum iron level, ferritin level, transferrin saturation, ceruloplasmin level and alpha-1 antitrypsin level. All patients also underwent tests for the presence of viral (antibodies to hepatitis B core antigen, hepatitis B surface antigen, antibodies to hepatitis $\mathrm{C}$ virus and antibodies to HIV) and autoimmune markers (antinuclear antibodies, smooth muscle antibodies and antimitochondrial antibodies). After undergoing these tests, 11 patients were excluded due to the presence of viral markers.

The remaining 33 patients who presented with altered aminotransferase levels (1.5 times the normal levels) on a second examination (after approximately 60 days) and whose alterations were attributed to obesity were included in the study protocol. These patients underwent a liver biopsy. Specimens were stained with hematoxylin-eosin, Sirius red (collagen identification) and Prussian blue (iron identification). All sections were examined by a single pathologist on two different occasions to assess intraobserver variability; the pathologist was not aware of the patients' data. Whenever disagreement was observed, the opinion of a second pathologist was requested. Four of these 33 patients presented with steatosis alone upon histological examination and were, therefore, excluded. As a result, 29 patients comprised the study.

The histological criteria for the diagnosis of NASH were the presence of macrovesicular steatosis associated with lobular inflammatory infiltrate with or without perisinusoidal fibrosis and the presence of hepatocellular injury, 
which was defined as the ballooning degeneration of hepatocytes affecting mainly zone 3 of the hepatic lobule (17).

Steatosis was considered mild when it involved onethird of the hepatic lobule, moderate when it involved oneto two-thirds of the hepatic lobule, and severe when it involved more than two-thirds of the hepatic lobule. The lobular inflammatory infiltrate was also classified according to the same criteria. To determine the degree of portal inflammation (mild, moderate or severe), both the number of portal spaces involved and the presence of activity in each portal space were considered.

The degree of fibrosis was assessed using a five-grade scale (18): grade 0 (none, normal connective tissue); grade 1 (mild, foci of pericellular fibrosis in zone 3 ); grade 2 (moderate, perivenular or pericellular fibrosis confined to zone 3 , in two regions with or without portal/periportal fibrosis); grade 3 (severe, bridging or septal fibrosis); and grade 4 (cirrhosis).

Patients were classified into four groups, according to the intensity of fibrosis and inflammatory findings: group I (mild lobular inflammatory infiltrate with mild or no involvement of portal spaces and mild or no fibrosis); group II (moderate lobular inflammatory infiltrate, with mild or moderate involvement of portal spaces and/or moderate fibrosis); group III (severe lobular inflammatory infiltrate and moderate or severe involvement of portal spaces and/or structural alterations due to the presence of fibrous septa); and group IV (cirrhosis).

Informed consent was obtained from all patients who agreed to participate in the study and who were included in the protocol. The research protocol was analyzed and approved by the Ethics Committee of the hospital.

For the statistical analysis, descriptive measurements were calculated, ie, means \pm SD for quantitative variables and percentages for categorical variables. Medians and interquartile ranges were determined for asymmetric quantitative variables. Intergroup comparisons were performed by the Student $t$ test for quantitative variables and by the $\chi^{2}$ test for categorical variables. A compound bar graph was used to compare histological grading and BMI. The level of significance was set at $\alpha=0.05$ for all analyses.

\section{RESULTS}

Of the 912 patients examined, 33 underwent liver biopsy. Four patients were excluded because they had steatosis only. As a result, 29 fulfilled the histological criteria established for the diagnosis of NASH $(3.18 \%$; $95 \%$ CI 2.2 to 4.6$)$. Of these 29 patients, 19 (65.52\%) were women. The mean age $( \pm \mathrm{SD})$ was $42.2 \pm 11.9$ years (range 19 to 61 years). The mean BMI was $38.4 \pm 7.4 \mathrm{~kg} / \mathrm{m}^{2}$. Among the patients with NASH, $15\left(51.7 \%\right.$ ) had a BMI of 30 to $35 \mathrm{~kg} / \mathrm{m}^{2}$ and 14 (48.3\%) had a BMI above $35 \mathrm{~kg} / \mathrm{m}^{2}\left(35 \mathrm{~kg} / \mathrm{m}^{2}\right.$ was used as the cutoff point for the correlation between degree of obesity and histological grading).

Mild to moderate elevation in aminotransferase levels was the most common alteration determined by liver func-

\begin{tabular}{|c|c|c|c|}
\hline Variables & $\begin{array}{l}\text { Mild } \\
\text { n (\%) }\end{array}$ & $\begin{array}{c}\text { Moderate } \\
\text { n (\%) }\end{array}$ & $\begin{array}{c}\text { Severe } \\
\text { n (\%) }\end{array}$ \\
\hline Macrovesicular steatosis & $1(3.4)$ & $15(51.7)$ & $13(44.8)$ \\
\hline Microvesicular steatosis & $14(48.3)$ & & \\
\hline Portal inflammation & $17(58.6)$ & $5(17.2)$ & $4(13.8)$ \\
\hline Lobular inflammation & $21(72.4)$ & $6(20.7)$ & $2(6.9)$ \\
\hline Mallory bodies & $7(24.1)$ & & \\
\hline Fibrosis & $13(44.8)$ & $4(13.8)$ & $4(13.8)$ \\
\hline Iron deposits & $2(6.9)$ & $1(3.4)$ & $2(6.9)$ \\
\hline
\end{tabular}

tion tests. The mean serum AST level was $52.3 \pm 21.2 \mathrm{IU}$, and the mean serum ALT level was 90.1 $\pm 37.9 \mathrm{IU}$.

The mean cholesterol concentration was $5.54 \pm 1.72 \mathrm{mmol} / \mathrm{L}$; 15 patients $(51.7 \%)$ had levels above the upper limit of normality $(5.17 \mathrm{mmol} / \mathrm{L})$. The mean triglyceride level was $2.14 \pm 1.75 \mathrm{mmol} / \mathrm{L} ; 16$ patients $(55.1 \%)$ had levels above the upper limit of normality $(1.8 \mathrm{mmol} / \mathrm{L})$. A total of 22 patients $(76 \%)$ had high cholesterol and/or triglyceride levels, but the mean values were close to normality.

The histological variables observed in the present study are described in Table 1.

When the cases were graded and classified according to our findings and criteria, 17 patients $(58.6 \%)$ were in group I, six (20.7\%) were in group II and six $(20.7 \%)$ were in group III. Although the formation of fibrous septa was seen in some patients, no cases of cirrhosis (group IV) were observed.

There was no correlation between BMI and histological grading, as shown in Figure 1. An association between the presence of dyslipidemia and the histological findings was not observed $(\mathrm{P}>0.05)$.

\section{DISCUSSION}

Obesity is a major public health problem in western countries (19), and it has long been correlated with hepatic alterations, especially steatosis (20-22). More recently, special attention has been devoted to the presence of more severe lesions associated with steatosis in obese patients, such as inflammatory infiltrates and fibrosis $(3,5,7,8)$. Also, the occurrence of cryptogenic cirrhosis in obese patients is currently attributed to the progression of NASH $(23,24)$.

The prevalence of NASH in obese patients is not known. Most studies on this subject are retrospective and include patients who underwent investigation for hepatic alterations, resulting in a selection bias $(1,3)$. Some studies reviewed hepatic biopsies that were compatible with alcoholic liver disease and then investigated patients retrospec- 


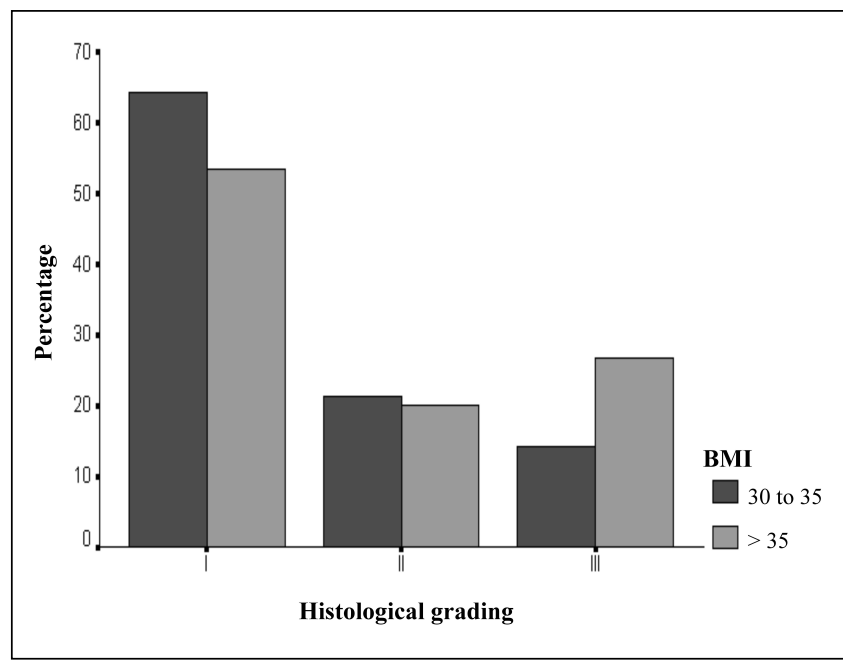

Figure 1) Comparison of the histological grading of groups with a body mass index (BMI) of 30 to $35 \mathrm{~kg} / \mathrm{m}^{2}$ and those with a BMI greater than $35 \mathrm{~kg} / \mathrm{m}^{2}$

tively to assess alcohol consumption; NASH was diagnosed after the exclusion of alcoholism $(2,5,12)$. Others were necropsy studies (11), in which the histological abnormalities observed may have resulted from the increased catabolism that is present in terminally ill patients. These studies $(1-3,5,11,12)$ reported a very strong association between obesity and NASH; however, all of them included patients with diabetes mellitus, and in many, hepatitis $\mathrm{C}$ infection was not ruled out.

Contrary to other studies, our sample excluded patients with diabetes mellitus. Therefore, the alterations observed are likely to be exclusively associated with obesity. In our sample of 912 obese individuals evaluated prospectively, NASH was diagnosed in $3.18 \%$ of the cases. These data probably underestimate the real prevalence of the disease, and the performance of biopsy in obese subjects with normal aminotransferase levels could possibly modify these results; however, we consider this procedure to be ethically contestable. The predominance of women $(65.25 \%$ of cases) is in accordance with the data reported by most investigators $(1,2,4,5,7,8,12)$.

Although the histological criteria for the diagnosis of NASH vary in different studies $(2-4,7,11,17)$, it is usually diagnosed by the presence of alcoholic hepatitis-like histological patterns in nonalcoholic individuals. In the present study, the minimal criterion for the diagnosis of NASH was the presence of macrovesicular steatosis associated with lobular inflammatory infiltrate and hepatocellular injury involving zone 3 of the hepatic lobule, according to the criteria established by the National Institutes of Health (17).

The presence of steatosis (usually moderate or severe), predominantly of the macrovesicular type, is observed in all cases of NASH $(1-3,12)$. In the present study, macrovesicular steatosis was graded as mild in only one patient and as moderate or severe in all other patients. Some degree of lobular inflammation was observed in all patients, although it was considered mild in 21 (72.4\%) (Table 1$)$.

The presence of mild or moderate fibrosis among patients with NASH has been reported in $76 \%$ to $100 \%$ of cases $(2,4,5,25,26)$, while severe fibrosis occurs in $15 \%$ to $50 \%$ of cases $(2,5,7,25,26)$. Progression to cirrhosis can be observed in more severe cases $(1-4,12,25)$. In the present study, 21 patients $(72.4 \%)$ presented with some degree of fibrosis, which was mild in 13 (44.8\%). Only four patients had severe fibrosis with the formation of septa (Table 1). Cirrhosis was not diagnosed in any patient.

Based on these variables, the patients were classified according to the intensity of the findings (groups I to IV). Although this classification is arbitrary, several other investigators have adopted a similar grading system to obtain uniform findings $(1,4,5)$. In our study, most patients were classified as group I (58.6\%). These findings are similar to those reported in the literature $(1-3,5,7)$. Recently, Brunt et al (27) proposed a new scoring system for grading and staging histological lesions.

Wanless and Lentz (11) reported an apparent positive association between degree of obesity and severity of histological findings. However, when the authors considered only obese patients without diabetes mellitus, this association was not verified. This finding suggests that diabetes mellitus, rather than the degree of obesity, is responsible for the greater severity of histological findings. Several investigators $(1,3,7)$ have not observed any association between severity of liver damage and degree of obesity. In a recent report, however, Angulo et al (18) evaluated independent risk factors for the formation of fibrosis and observed a significant association with degree of obesity, advanced age and presence of diabetes mellitus. Ratziu et al (28) observed that degree of obesity, age over 50 years, and levels of triglycerides and ALT are also independent risk factors for the development of septal fibrosis and cirrhosis in obese patients. In the present study, we did not find an association between degree of obesity and histological grading. However, patients with a BMI greater than $35 \mathrm{~kg} / \mathrm{m}^{2}$ tended to have more serious findings; this observation could be significant in a larger sample (Figure 1).

The presence of dyslipidemia (hypercholesterolemia, hypertriglyceridemia or both) is a frequent finding among patients with NASH - it has been reported in $20 \%$ to $80 \%$ of cases $(1-5,7,11,25)$. In our study, a significant number of patients presented with high levels of cholesterol and/or triglycerides $(76 \%)$. It is not clear whether this condition occurs only in association with obesity or whether it plays a role in the pathogenesis of NASH (29). In the present study, as well as in that of Angulo et al (18), no association was detected between severity of hepatic histological changes and presence of dyslipidemia.

\section{CONCLUSIONS}

$\mathrm{NASH}$ should always be considered in nondiabetic obese patients who present with altered aminotransferase levels. Although most nondiabetic obese patients with NASH do 
not present with severe histological findings, they should be closely monitored, because NASH may progress to a more severe form.

ACKNOWLEDGEMENTS: We are grateful to Miguel Carneiro Moura, from the School of Medicine of Lisbon, Portugal, for revising our manuscript.

\section{REFERENCES}

1. Schaffner F, Adler M. Fatty liver hepatitis and cirrhosis in obese patients. Am J Med 1979;67:811-6.

2. Ludwig J, Viggiano TR, Mcgill DB, Ott B. Nonalcoholic steatohepatitis. Mayo Clinic experiences with a hitherto unnamed disease. Mayo Clin Proc 1980;55:434-8.

3. Bacon BR, Farahvash MJ, Janney CG, Neuschwander-Tetri BA. Nonalcoholic steatohepatitis: an expanded clinical entity. Gastroenterology 1994;107:1103-9.

4. Diehl AM, Goodman Z, Ishak KG. Alcohol-like liver disease in nonalcoholics. A clinical and histologic comparison with alcoholinduced liver injury. Gastroenterology 1988;95:1056-62.

5. Lee RG. Nonalcoholic steatohepatitis: a study of 49 patients. Hum Pathol 1989;20:594-8.

6. Lieverse RJ, Jansen JBM, Masclee AAM, Lamers CB. Gastrointestinal disturbances with obesity. Scand J Gastroenterol 1993;28:53-8.

7. Powell EE, Cooksley WG, Hanson R, Searle J, Halliday JW, Powell L. The natural history of nonalcoholic steatohepatitis: a follow-up study of forty-two patients for up to 21 years. Hepatology 1990;11:74-80.

8. Sánchez MD, Herce BC, Algibez AM, et al. Esteatohepatitis no alcohólica. Evolución clínica e histológica a medio plazo de diez pacientes. Med Clin (Barc) 1991;96:733-6.

9. Steenbergen WV, Lanckmans S. Liver disturbances in obesity and diabetes mellitus. Int J Obes 1995;19:27-36.

10. Teli MR, James OFW, Burt AD, Bennett MK, Day CP. The natural history of nonalcoholic fatty liver: a follow-up study. Hepatology 1995;22:1714-9.

11. Wanless IR, Lentz JS. Fatty liver hepatitis (steatohepatitis) and obesity: an autopsy study with analysis of risk factors. Hepatology 1990;12:1106-10

12. Nonomura A, Mizukami Y, Unoura M, Kobayashi K, Takeda Y, Takeda R. Clinicopathologic study of alcohol-like liver disease in non-alcoholics; non-alcoholic steatohepatitis and fibrosis. Gastroenterol Jpn 1992;27:521-8.
13. Matteoni CA, Younossi ZM, Gramlich T, Boparai N, Liu YC, McCullough AJ. Nonalcoholic fatty liver disease: a spectrum of clinical and pathological severity. Gastroenterology 1999;116:1413-9.

14. Daniel S, Ben-Menachem T, Vasudevan G, Ma CK, Blumenkehl M. Prospective evaluation of unexplained chronic liver transaminase abnormalities in asymptomatic and symptomatic patients. Am J Gastroenterol 1999;94:3010-4.

15. Monteiro JC. Obesidade: diagnóstico, métodos e fundamentos. In: Obesidade. São Paulo: Lemos, 1998:31-53.

16. Report of the Expert Committee on the Diagnosis and Classification of Diabetes Mellitus. Diabetes Care 1997;20:1183-97.

17. National Institutes of Health. Symposium on Non-Alcoholic Steatohepatitis. Bethesda: Syllabus, 1998.

18. Angulo P, Keach JC, Batts KP, Lindor KD. Independent predictors of liver fibrosis in patients with nonalcoholic steatohepatitis. Hepatology 1999;30:1356-62.

19. Monteiro CA. Epidemiologia da obesidade. In: Obesidade. São Paulo: Lemos, 1998:3-30.

20. Galambos JT, Wills CE. Relationship between 505 paired liver tests and biopsies in 242 obese patients. Gastroenterology 1978;74:1191-5.

21. Klain J, Fraser D, Goldstein J, et al. Liver histology abnormalities in the morbidly obese. Hepatology 1989;5:873-6.

22. Silverman JF, O'Brien KF, Long S, et al. Liver pathology in morbidly obese patients with and without diabetes. Am J Gastroenterol 1990;85:1349-55.

23. Caldwell SH, Oelsner DH, Iezzoni JC, Hespenheide EE, Battle EH, Driscoll CJ. Cryptogenic cirrhosis: clinical characterization and risk factors for underlying disease. Hepatology 1999;29:664-9.

24. Poonawala A, Nair SP, Thuluvath PJ. Prevalence of obesity and diabetes in patients with cryptogenic cirrhosis: a case-control study. Hepatology 2000;32:689-92.

25. Pinto HC, Baptista A, Camilo ME, Valente A, Saragoça A, Moura MC. Nonalcoholic steatohepatitis. Clinicopathological comparison with alcoholic hepatitis in ambulatory and hospitalized patients. Dig Dis Sci 1996;41:172-9.

26. Itoh S, Yougel T, Kawagoe K. Comparison between nonalcoholic steatohepatitis and alcoholic hepatitis. Am J Gastroenterol 1987;82:650-4.

27. Brunt EM, Janney CG, Di Bisceglie AM, Neuschwander-Tetri BA, Bacon B. Nonalcoholic steatohepatitis: a proposal for grading and staging the histological lesions. Am J Gastroenterol 1999;94:2467-74.

28. Ratziu V, Giral P, Charlotte F, et al. Liver fibrosis in overweight patients. Gastroenterology 2000;118:1117-23.

29. Sheth SG, Gordon FD, Chopra S. Nonalcoholic steatohepatitis. Ann Intern Med 1997;126:137-45. 


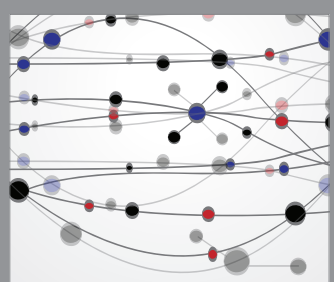

The Scientific World Journal
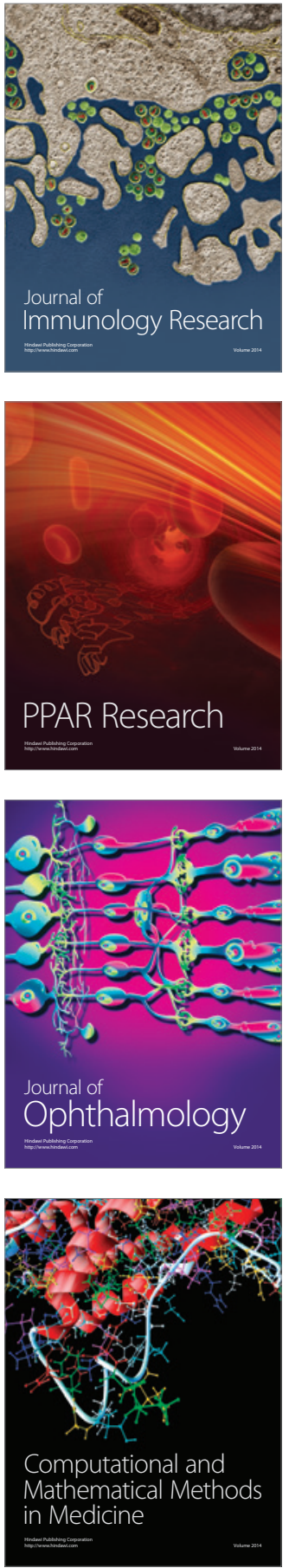

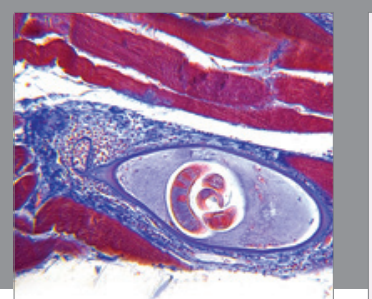

Gastroenterology Research and Practice

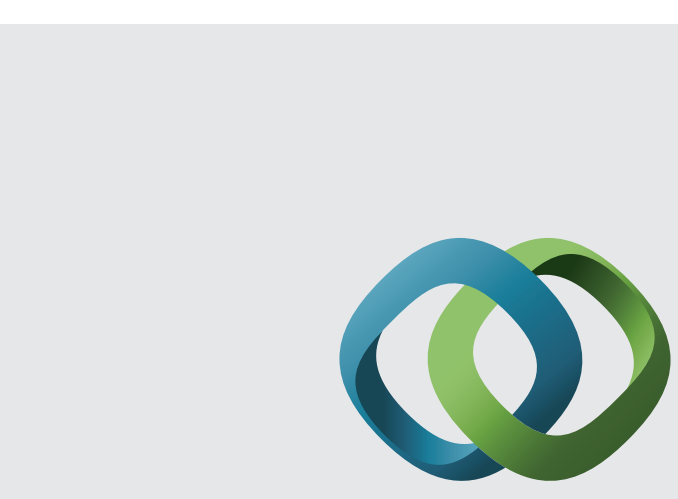

\section{Hindawi}

Submit your manuscripts at

http://www.hindawi.com
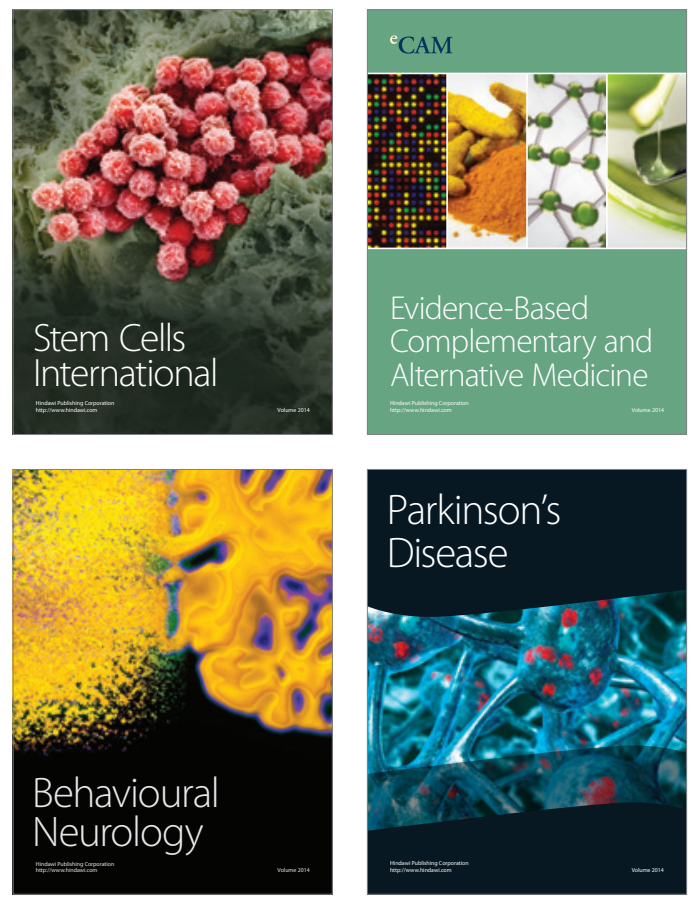
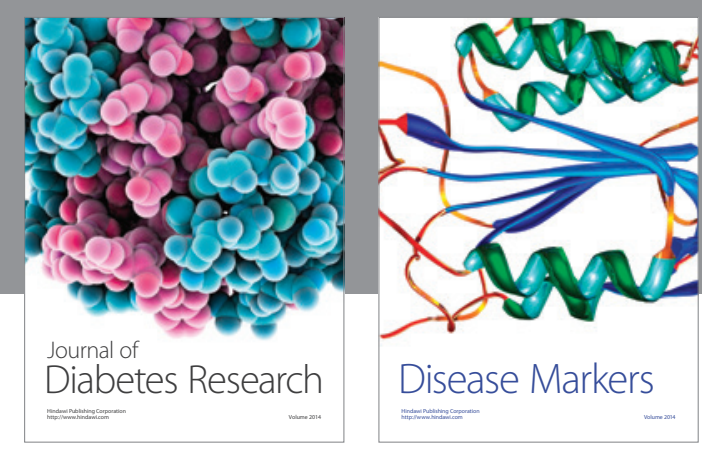

Disease Markers
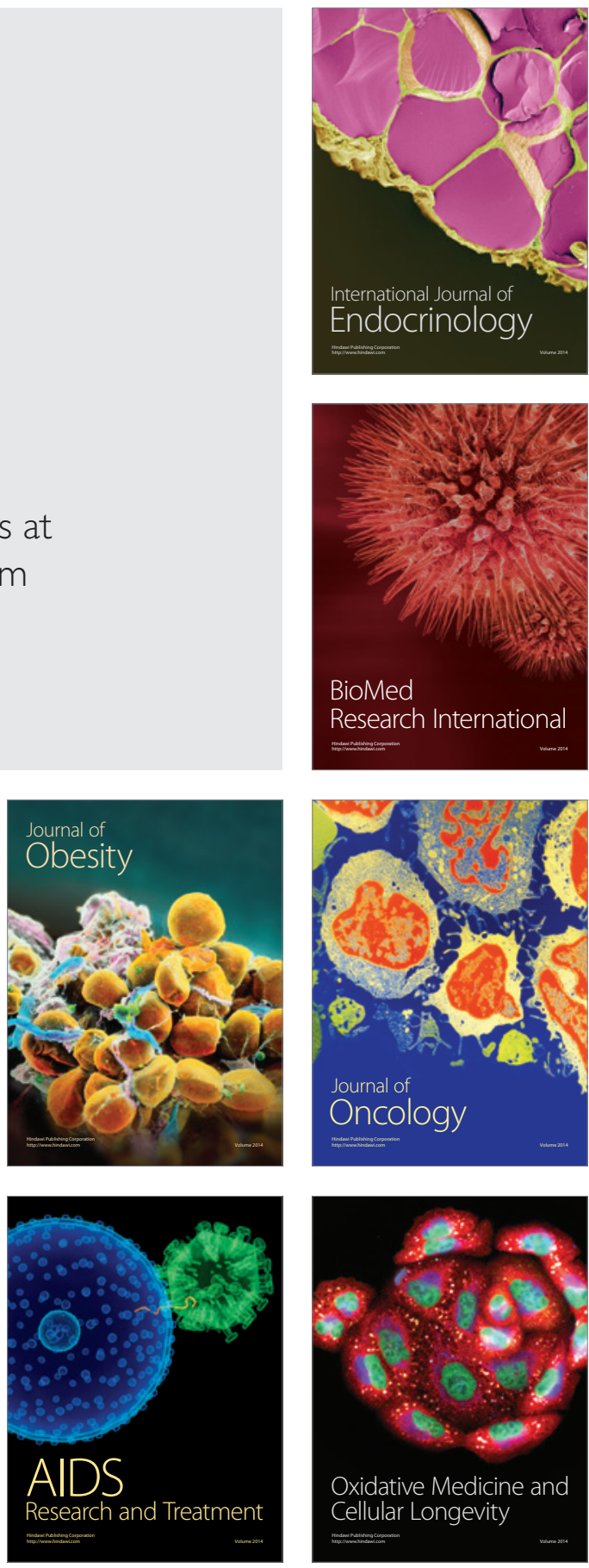